\title{
Dimensionalizing the Information and Communication Technology Adoption Construct
}

\author{
${ }^{1}$ Waribugo Sylva, ${ }^{2}$ Anyanwu A.C. Success \\ ${ }^{1,2}$ Department of Management, University of Port Harcourt, Nigeria
}

\begin{abstract}
This study was conducted to determine the principal components of the information and communication technology (ICT) adoption practices in a developing country. A nineteen- item instrument was developed from extant current literature. Eight hundred and fifty copies of the structured questionnaire were administered to teaching and nonteaching staff of two faculties from the University of Port Harcourt and Rivers State University of Science and Technology, both located in Rivers State. Out of the number distributed, 435 were completed and returned. To determine the dimensions of ICT adoption, an exploratory factor analysis (EFA) was conducted through the application of principal component analysis (PCA). From the analysis, three factors were extracted which account for $68.8 \%$ of the total variance. Thus, the researchers named the factors: virtual learning, e-learning and networking practices.
\end{abstract}

Keywords: ICT adoption, Virtual learning, E-learning, Networking, PCA

\section{Introduction}

Information and communication technology is highly influential in today's business operating environment. With the ever dynamic and aggressively competitive business environment, there is an increase in the application of ICT among businesses. The adoption of ICTis gradually changing the production system, marketing pattern, consumption structure and business methods generally (Kazi, 2007). Similarly, Alberto and Fernando (2007) asserted that the adoption of appropriate ICT leads to improvement in the competitiveness of an organization. Specifically, the Internet encourages faster transactions and enhances communication at a global level.

As noted by Meenakshi (2013), ICT has penetrated the modern corporations' organizational processes, structures, and general operations. The success or failure of businesses now depends on their ability (or inability) to successfully adopt ICT in their daily routines. In the educational institutions, the effective adoption of ICT have being shown to improve the efficiency of teachers and enhance students learning, while creating a cordial teacher -student relationships (Chong, Pervan, \& Bauer, 2001). Similarly, Mutsaers et al. (1998) submit that successful educational institutions are those that have realized that information and communication technology (ICT) is an important factor in the teaching - learning processes, this has aided their competitiveness and being an added advantage against global educational institutes.

In the current educational system, it is no longer possible to disregard the critical position ICT occupies in the teaching - learning process. Administrators of higher institutions are confronted with the task of subsuming ICT into the various processes of school administration, starting from admission, through graduation. At the point of admission, applicants are made to apply through the internet, while most schools in the country adopt computer-based test (CBT) to screen applicants for admission into their programmes. Some semester examinations are also written online, while students now view their results from their phones and laptops via the school website. Most experts in the educational sector consent that, if properly implemented, ICT possess great impact which can lead to improvement in the teaching and learning aspect (Agabi \& Uche, 2006).

From the above, it can be inferred that ICT has an important role in the successful management of educational institutions. In the light of the perennial challenges of students over-population, inadequacy of teaching personnel and materials, poor 
funding and subsequent infrastructural deficit which has almost crippled the Nigerian university system, it seems leveraging on ICT could be the panacea for these problems. However, as submitted by Mbakwe and Okeke (2007) and supported by Aderibigbe (2008) there is a big gap in the adoption of ICT between educational institutions in developed and developing countries. Educational institutions in developing countries are still lacking in the adoption of ICT and are still skeptical about some aspects of ICT. Also, measuring ICT adoption practices in educational institutions in developing countries has been a great challenge, as most scholars rather focus on the enablers and barriers to ICT adoption (Hollenstein, 2004; Ukonu, Wogu, \& Obayi, 2012).

Several scholars have suggested numerous dimensions of ICT adoption including e-learning, virtual learning and networking and developed scales to measure the constructs (e.g., Radcliffe, 2002; Keegwe, \& Wachira, 2008; Olojo, Adewumi \& Ajisola, 2012; Olibie, Ezoem \& Ekene, 2014). Despite these attempts, there seems to be no generally agreed scale to measure ICT adoption practices, especially in the Nigerian educational sector. Also, as earlier stated, most of the extant literature available, focus on the barriers and enablers of ICT (e.g. Hollenstein, 2004; Ahuja, Yang, \& Shankur, 2009) without dimensionalizing the construct into factors. Therefore, this study is aimed at filling this gap by developing an ICT adoption scale which has psychometric integrity; and compartmentalizing the observed indicators into factors through the use of principal component analysis.

\section{Literature Review and Hypotheses Development}

Several studies have highlighted various benefits that could be derived from the adoption of ICT by schools and business enterprises (e.g. Ritchie \& Brindley, 2000; Sparkes \& Thomas 2001; MacGregor, 2004). However, many of these studies conclude that the pay-offs, in most cases, do not show in terms of immediate impact. This means that such benefits are usually not felt by owner/managers at the time of adoption, but on the long run. According to Olayemi and Omotayo (2012), ICTaids in the improvement and enhancement of the managerial functions of schools top officers. For instance, the use of computers can help in a faster dissemination of information, which will lead to the achievement of better results.

Studies by Ritchie and Brindley (2000), and Quayle (2002) show that businesses stand to benefit tremendously from the adoption of ICT in their processes. This is so because the adoption of ICT enhances business relationships with customers, suppliers, employees and new markets. This relationship is likened to the teacher/students relationship in higher institutions.

The impact of Information and communication Technology is seen in all facets of our daily lives. Effect of ICT usage is observed in the fashion industry, movies, arts, medicine and virtually every other facet of our society. As noted by Mbakwem and Okeke (2007), ICT has revolutionized our society and the way things are being done. Correspondingly, our demands have changed along with the changes brought by the emergence of ICT. Moreover, the demand in the educational sector has changed with the advent of ICT with teachers using diverse ICTplatforms in the educational process. Likewise, Olayemi and Omotayo (2012) suggested that ICT adopted by the school management help to improve “teachers' effective delivery of services, effective communication, effective maintenance of sound students record system and maintaining academic planning record system among others". ICT adoption helps to fulfill the primary objective of schools, which is to achieve teaching and learning (Jaiyeoba, 2006).

According to Aboderin (2009) information and communication technology incorporate the general fields of information and communications through the medium of computer and telecommunication systems; it also includes equipment that is been used by organizations or individuals to process data.Therefore, ICT could be defined as any medium that eases the communication process by assisting in encapsulating, transforming and dispatching information in electrical form. The acquisition of these technologies in the day to day management of the organizations is known as ICT adoption.

An extensive review of literature led to the identification of several dimensions of ICT adoption. These include: the Internet, networking, virtual learning, e-learning, information sharing, ICT infrastructure, data security (Egbu, 2001; Root, \& Thorpe, 2001). However, in this study three of the factors identified from literature and listed above were investigated if they can adequately describe ICT adoption construct. 


\subsection{Virtual Learning}

This is the process of learning through electronic methods including the use of email, web portals/platforms, e-portfolios and social media such as Facebook, Twitter.According to Lokie (2011), virtual learning is the acquisition of knowledge that is limited to the classroom. It involves the option of learning by means of "internet facilities, platforms, satellite links, and related system to access, analyze, create, exchange, and use data, information, and knowledge in ways which until recently, were almost unimaginable". Olibie, Ozoem and Ekene (2014) added that virtual learning has no definite definition as it continuously evolves. They further noted that virtual learning involves learning via the adoption of new technologies such as internet blogs, wikis, and any other web platforms.

Virtual learning is carried out in an environment known as virtual learning environments (VLEs). As submitted by Pelet and Lecarte (2012), virtual learning environments are "computer-based environments that are relatively open systems, allowing interactions and encounters with other participants and providing access to a wide range of resources". Other names for VLEs are "course management systems (CMS), learning platforms (LP) or learning management systems (LMS)" (Olibie, Ozoem, \& Ekene, 2014). VLEs are gaining popularity in institutions of higher learning across the globe.

\subsection{E-Learning}

Electronic learning (E-learning) refers to the adoption of electronic media in whatever form to proffer solutions and create knowledge which impacts on the general performance of the learner. There is increased popularity of e-learning among school administrators and students, this mainly due to the fact that e-learning creates a flexible atmosphere where teaching and learning can take place at any given time and place (Means, Toyama, Murphy, \& Baki, 2013). According to Olojo, Adewumi and Ajisola (2012), e-learning is similar to virtual learning as it involves the use of graphics, texts, simulation, animation, video in the learning process. However, e-learning is different from virtual learning as it also involves the adoption of audio materials in learning. It also involves collaborations between teachers and students, and collaboration between educational institutions.

E-learning is known by other names such as web-based learning, computer assisted learning, internet-based learning, audio messaging and online learning. E-learning creates an environment where learners can be involved in active and innovative learning with like minds at any time and in a controlled environment.

As asserted by Markus(2008), e-learning is defined as "a learning process created by interaction with digitally delivered content, network-based services and tutoring support”. In other words, e-learning is any form of technology that aids learning through the use of computers either involving distance learning or learning in a confined area (classroom setting). In summary, e-learning can be said to be any form of technology-assisted learning. Olojo, Ajisola and Adewumi (2012) submit that e-learning is transcending from the traditional teaching methods to "ICT-based personalized, flexible, individual, self-organized, collaborative learning based on a community of learners, teachers, facilitators, experts".

\subsection{Networking}

Networking is an important aspect of ICT adoption practices. Networking practices include all actions taken by the organization to integrate computers, printers, scanners, and other equipment for the purpose of communication. Computer networking via the internet brings collaborations among teachers and students. According to the National Research Council (2000), networking platforms in schools include: electronic mail (e-mail), chat rooms, having virtual online meetings, conference calls, and other forms of digital communication. The Council also posited that networking helps in the timely flow of information between members of an organization and even with other organizations. For Chen, Boase and Wellman (2002) Internet networking is "the connectivity of people all over the world using internet". The process of connecting people and organizations around the globe via computer interface is known as computer networking.

Having reviewed existing literature, on the supposed three factors of ICT adoption practices, it was therefore hypothesized that: 
H1: Virtual learning, e-learning and networking cannot sufficiently describe information and communication technology adoption practices scale

H2: The indicators that fall under virtual learning, e-learning and networking cannot sufficiently describe these latent variables

\section{Methodology}

\subsection{Sample and Data Collection Procedure}

The cross-sectional survey research design was adopted, wherein data concerning the variables were generated from the respondents at only one time period. Data were generated using a structured questionnaire and administered at a single point in time. The respondents for this study are drawn from educational institutions of higher learning. A total 850 copies of the questionnaire were distributed to scholars working with the Faculties of Management Sciences, and Education of University of Port Harcourt and Rivers State University of Science and Technology. Out of which 585 were teaching staff, while 265 were non-teaching staff of the universities. The teaching staff comprises HODs of departments under the two faculties and other lecturers, while the non-teaching staff including administrative officers and computer operators. These sets of respondents were chosen since the study has to do with the ICT adoption practices in the teaching and learning process in the school.

435 copies of the completed questionnaire were received, 296 from the teaching staff, 139 from the non-teaching members of staff. This constitutes a little above half the population at $51 \%$. Specifically, $51 \%$ for the teaching staff and $52 \%$ for the non-teaching staff, the rate of response is sufficient for the analysis to be conducted (Alegre, et al., 2013). Thus, the 435 respondents that returned their copies served as the sample size for this study.

\subsection{Operational Measures of the Variable}

A nineteen - item instrument was developed for this study. The items were self-developed from an extensive review of literature on information and communication technology adoption practices. Some items were adopted from the “Students' Virtual Learning Awareness Questionnaire” developed by Olibie, Ezoem and Ekene (2014). Examples of such items include: "Researching for course content information from on-line libraries"; "Learning through network technologies from cell phones". Items were also adopted from Ahuja, Yang and Shankar (2009), including "Pinging/chats with colleagues about quizzes, examinations, and assignments"; "We use 3D/4D visualization techniques as a communication tool". The responses to each of the items were rated using a 5-point Likert-scale labeled as follows: $5=$ Strongly agree, to 1 = Strongly disagree.

\subsection{Validity and Reliability of the Instrument}

Validity is referred to as the quality of information or data gathering instrument or procedure that enables it measure effectively and accurately what it is supposed to measure. Therefore, in order to ascertain the internal, external, content and construct validity of this work, the instrument was given to several lecturers in the faculty of management sciences, the University of Port Harcourt to examine and make recommendations. These recommendations led to the addition of two more items to the initial number of items generated from literature. Also, to ascertain the validity of the measuring instrument, an additional section was provided for the respondents to suggest any other ICT adoption practices not covered in the questionnaire. The above steps help to justify face and content validity of the measuring instrument (Neill, 2008; Donald, et al., 2011).

Reliability is defined as the degree of consistency of an instrument or a procedure (Golafshani, 2003; Umoh \& Waribugo, 2016). The reliability of the questionnaire was ascertained with the use of the test-re-test reliability technique. The initial instrument was administered to some lecturers in the faculty of management sciences, University of Port Harcourt. Based on their responses, constructive criticism and recommendations, a modified instrument was developed which was then administered to different respondents and their responses correlated using the Cronbach Alpha, the items that returns alpha values of .7 and above were adopted for the final instrument. This criterion helps to ascertain that the instrument is reliable and satisfies the conditions suggested by notable scholars (e.g. Nunnaly, 1978; Nunnaly \& Bernstein, 1994; Creswell \& Miller, 2000). 


\subsection{Data Analysis Techniques}

The principal component analysis (PCA) was used to analyze the data and factorized the items into variables. This is in line with the aim of this study, which seeks to identify the items that can cluster to form factors. In this instance, therefore, the use of principal component analysis is appropriate for this study (Pallant, 2013). The analysis was conducted through the aid of Statistical Package for Social Sciences (SPSS) version 22.

\section{Data and analysis}

\subsection{Data Screening}

The data generated was screened for univariate outliers. After the initial screening, a total useable size of 216 was realized. This provides a ratio of over 11 cases per item, which satisfied the barest minimal amount of 10 cases per item for factor analysis to be conducted as suggested by Nunnally (1978). Similarly, Tabacknick and Fidell (2001) suggested a ratio of 5 cases to 1 item. However, Stevens (1996) went further to look at the reliability of factor structures, stating that the factors generated should give an alpha value of not less than .80, particularly, if the number of cases is less than 150 . The data for this study met all the above mentioned conditions and therefore was suitable for this study.

\subsection{Factor Analysis}

Initial examination of the 19 - item ICT Adoption scale was carried out. All necessary steps were taken to ensure that the data was factorable and suitable for analyses. In the first instance, it was ascertained that several of the 19 individual items correlated with each other with a minimum value of .3 and above, thereby meeting the condition for worthiness of a data for factorability as suggested by Tabachnick and Fidell (2001), and Pallant (2013) (Please see Appendix 2, table A).

Secondly, an examination of the Kaiser-Meyer-Olkin measure of sampling adequacy revealed a value of .75, satisfying the basic recommended value of .6 suggested by (Kaiser, 1970, 1974; Hair, et al., 1998). Similarly, the Bartlett's test of sphericity was significant at $(\chi 2(153)=8288.543, p<.05)$. These are shown in the table 4.2.1 below:

Table 1: KMO and Bartlett's Test

\begin{tabular}{|l|l|}
\hline Kaiser-Meyer-Olkin Measure of Sampling Adequacy & .75 \\
Bartlett's Test of Approx. Chi-Square & 8288.543 \\
Sphericity df & 153 \\
Sig. & .000 \\
\hline
\end{tabular}

The data was confirmed suitable for the analyses after the prior tests reported above. Therefore, Principal components analysis was used to identify and dimensionalize ICT adoption practices into the factors which have given rise to the development of information and communication technology adoption practices scale (ICTAP) scale.

The initial analysis shown in table 4.3.2 below, reveals that only five components can be extracted based on the Kaiser's criterion, which prescribed eigenvalues of 1 and above. The first five components recorded eigenvalues of 5.509, 5.156, $2.405,1.327$, and 1.029 respectively, which explained a cumulative variance of $81.18 \%$ as shown in table A (see appendix 2). However, an examination of the scree plot shows a break between component three and four - meaning that components one, two and three explain more of the total variance $(68.78 \%)$ than the remaining components. Also, a critical view of the component matrix table shows that components one, two, and three have more items loadings of .4 and above, with component 1 having a seven- item load, component 2 amassing six-item load and component 3 having four-item load. However, components 4 and 5 have two- and one-item load respectively. Therefore, it is appropriate for components 1, 2, and 3 to be retained for the final stage of analysis. 
Waribugo Sylva, Anyanwu A.C. Success

Table 2: Component Matrix ${ }^{\mathrm{a}}$

\begin{tabular}{|c|c|c|c|c|c|}
\hline & \multicolumn{5}{|c|}{ Component } \\
\hline & 1 & 2 & 3 & 4 & 5 \\
\hline ICTAP15 & .931 & & & & \\
\hline ICTAP17 & .925 & & & & \\
\hline ICTAP16 & .921 & & -.301 & & \\
\hline ICTAP14 & .892 & & -.314 & & \\
\hline ICTAP18 & .860 & & & & \\
\hline ICTAP13 & .631 & & & & .388 \\
\hline ICTAP12 & .611 & & & -.482 & \\
\hline ICTAP5 & & .952 & & & \\
\hline ICTAP6 & & .936 & & & \\
\hline ICTAP4 & & .911 & & & \\
\hline ICTAP7 & & .911 & & & \\
\hline ICTAP8 & & .908 & & & \\
\hline ICTAP9 & & .506 & & & -.451 \\
\hline ICTAP10 & .416 & & .643 & & \\
\hline ICTAP1 & & .347 & .560 & & -.369 \\
\hline ICTAP2 & & .452 & .556 & & \\
\hline ICTAP19 & & & & .652 & .547 \\
\hline ICTAP11 & .381 & & .474 & -.558 & \\
\hline ICTAP3 & .352 & .436 & .437 & .492 & \\
\hline
\end{tabular}

Extraction Method: Principal Component Analysis.

a. 5 components extracted.

Table 3: Rotated Component Matrix ${ }^{\mathrm{a}}$

\begin{tabular}{|l|r|r|r|}
\hline & \multicolumn{3}{|c|}{ Component } \\
\cline { 2 - 4 } & 1 & 2 & 3 \\
\hline ICTAP15 & $\mathbf{. 9 7 9}$ & & \\
ICTAP16 & $\mathbf{. 9 7 4}$ & & \\
ICTAP17 & $\mathbf{. 9 7 3}$ & & \\
ICTAP14 & $\mathbf{. 9 4 6}$ & & \\
ICTAP18 & $\mathbf{. 8 9 1}$ & & \\
ICTAP12 & $\mathbf{. 4 9 0}$ & & $\mathbf{4 0 7}$ \\
ICTAP5 & & $\mathbf{. 9 6 4}$ & \\
ICTAP4 & & $\mathbf{. 9 4 9}$ & \\
ICTAP7 & & $\mathbf{. 9 4 7}$ & \\
ICTAP6 & & $\mathbf{. 9 4 3}$ & \\
ICTAP8 & & $\mathbf{. 9 3 0}$ & \\
ICTAP10 & & & $\mathbf{. 7 7 5}$ \\
ICTAP2 & & & $\mathbf{. 7 3 0}$ \\
ICTAP1 & & & $\mathbf{. 6 9 0}$ \\
ICTAP3 & & & $\mathbf{. 6 5 3}$ \\
ICTAP11 & & & $\mathbf{. 5 6 2}$ \\
ICTAP13 & .478 & & $\mathbf{. 4 8 9}$ \\
ICTAP9 & & & \\
ICTAP19 & & & \\
\hline
\end{tabular}

Extraction Method: Principal Component Analysis. Rotation Method: Varimax with Kaiser Normalization.

a. Rotation converged in 5 iterations. 


\subsubsection{Factor Rotation and Interpretation}

In this final stage of analysis, the software was instructed to extract three factors which were rotated using Varimax and Oblimin rotation techniques.

The analyses reveal that the difference between the two rotation methods was insignificant. However, it was decided that varimax rotation solution be adopted since it has a stronger items load among the components. The final analysis indicated that the three factors components explained a cumulative variance of $68.8 \%$.

Item 19 was eliminated after the final test because it did not contribute to a simple factor structure and it failed to score the minimum requirement of obtaining an initial factor loading of .4. It also failed to score items cross-loading of .3 or above. The remaining 18 items made up the information and communication technology adoption practices scale (ICTAP) scale

Out of the 18 items in the scale, 15 of them have a primary loading solutions of .5 and above, while 3 have factor loadings of less than .5 (items 9, 12 and 13). However, these items had a strong primary loading of above .7. The factor loading matrix for this final solution is presented in Table 4.3.3 above.

\subsubsection{Summary of Findings}

From the analysis, items 12,14,15, 16, 17 and 18 fall under the first factor, while items 4, 5, 6, 7, 8 belong to the second factor, and items 1, 2, 3, 9, 10 and 13 fall under the last factor. These items made the .4 criteria for primary factor loadings and cluster under the factors. Therefore, these factors were retained and named thus: 1. virtual learning, 2. e-learning, and 3. networking. These findings negate the hypotheses earlier stated in this study

\subsubsection{Test for Reliability of the Principal Items}

Internal consistency for each of the scales was examined using Cronbach's alpha. The alpha values were moderate: .936 for virtual learning (6 items), .978 for e-learning (5 items), and .762 for networking (7 items). No substantial increases in alpha for any of the scales could have been achieved by eliminating more items.

Table 4: Cronbach Values for Extracted Factors

\begin{tabular}{|c|c|c|}
\hline Factor & No. of Items & Alpha Value \\
\hline Virtual Learning & 6 & .936 \\
\hline E-learning & 5 & .978 \\
\hline Networking & 7 & .762 \\
\hline
\end{tabular}

Contrary to the first hypothesis, these items are adequate to describe and measure the three factors of ICT adoption. Also, the second hypothesis, which states that virtual learning, e-learning and computer networking cannot sufficiently describe the ICT adoption construct was rejected and its alternative accepted.

Overall, the analyses have shown that the scale developed to measure the three distinct factors of virtual learning, elearning and computer networking can be used to describe ICT adoption practices in the Nigerian university system.

\section{Conclusion and Recommendations}

This study centered on the concept of information and communication technology adoption practices in the Nigerian university system. Hypotheses were formulated that, the items cannot adequately describe ICT adoption practices. Also, it was hypothesized that virtual learning, e-learning and computer networking factors cannot adequately represent ICT adoption practices. However, after conducting analyses, it was revealed that out of the 19 items generated, only one was dropped with the remaining 18 items falling into three distinct factors (virtual learning, e-learning and computer networking). The factors of ICT adoption practices(ICTAP), as dimensionalized in this study, confirm the earlier studies by other scholars that virtual learning, e-learning and computer networking can conveniently measure ICT adoption practices (e.g. Ahuja, Yang \& Shankar, 2009; Olibie, Ezoem \& Ekene, 2014). Also, the study confirmed that, the 18 items instrument can adequately be used to measure ICT adoption practices in Nigerian universities.

This work has contributed to the burgeoning literature on ICT as an exploratory study by developing a scale that can be used to measure ICT adoption practices. Despite the fact that, the purpose of this study was achieved, the researcher 
encountered some limitations while carrying out this study. As a result of these constraining factors the following recommendations are made:

1. Further research should be carried out using confirmatory factor analysis (CFA) with structural equation modeling (SEM).

2. Also, data should be collected from other faculties and possibly from other schools as well.

3. This three-factor-model should be used to assess students' performance in the university system - that is, to ascertain the impact ICT adoption has on students' performance in the universities.

4. Similar study should be conducted in other sectors such as the banking and manufacturing sectors.

\section{References}

- Aderibigbe, F. (2008). The place of information and communication technology in the preparation of examination results. Being the text of a paper delivered on one day seminar organized by the University of Ado-Ekiti, Nigeria on Boosting the Job Performance of Academic Staff. March 2008.

- Agabi, O. G. \& Uche, C.M. (2006). ICT adoption and information quality in effective university management. Nigerian Journal of Educational Administration and Planning(NAEAP) 6, (2), 45-68.

- Ahuja, V., Yang, J. \& Shankar, R. (2009) Study of ICT adoption for building project management in the Indian construction industry. Automation in Construction, 18(4), 415 423, CrossRef

- Alberto, B. M. \& Fernando, L. L. (2007). A firm-level analysis of determinants of ICT adoption in Spain. Technovation, 27, 352-366, CrossRef

- Chen, W., Boase, J. \& Wellman, B. (2002). The global villagers: Comparing internet users and uses around the world, in Wellman, B. and Haythornthwaite, C. (eds) The Internet in Everyday Life, Oxford: Blackwell, 74-113, CrossRef

- Chong, S., Pervan, G., \&Bauer, C. (2001). Implementation success of internet-based electronic commerce for small-and medium-sized enterprises in Australia. $14^{\text {th }}$ International Bled Electronic Commerce Conference, Bled, Slovenia, June 25-26.

- Egbu, C., Gaskell, C. \& Howes, J. (2001). The role of organizational culture and motivation inthe effective utilization of information technology for team working in construction. Proc. OfARCOM $7^{\text {th }}$ Annual Conference, University of Salford, Manchester, UK, 1, 91100.

- Hair, J. F., Tatham, R. L., Anderson, R. E., \& Black, W. C. (1998). Multivariate data analysis (5 ${ }^{\text {th }}$ edn). New York: Prentice Hall.

- Hollenstein, H. (2004). Determinants of the adoption of information and communication technologies (ICT): an empirical analysis based on firm-level data for the Swiss business sector. Structural Change and Economic Dynamics, 15, 315-42, $\underline{\text { CrossRef }}$

- Kaiser, H. (1970) A second generation little jiffy. Psychometrika, 35(4), 401-415, CrossRef

- Kaiser, H. (1974) An index of factorial simplicity. Psychometrika, 39(1), 31-36, CrossRef

- Kazi, A. U. (2007). Small and medium business enterprises and the use and adoption of information and communication technology: A study of legal issues and legal perspectives. International Journal of Organisational Behaviour, 12(1), 144-160.

- Keegwe, O., \& Wachira, P. (2008). The use of computer tools to support meaningful learning. AACE Journal, 16(1), 77-92.

- Lokie, J. M. (2011). Examining student achievement and motivation using internet-based inquiry in the classroom. Open Access Theses and Dissertations from the College of Education and Human Sciences. Paper 102.

- Markus, B. (2008). Thinking about e-learning. Proceedings FIG International Workshop. Sharing GoodPractices: E-learning in Surveying, Geo-information Sciences and Land Administration, 11-13 June 2008, ITC, Enschede, the Netherlands.

- Means, B., Toyama,Y., Murphy, R.F.,\& Baki, M., (2013).The effectiveness of online and blended learning: A meta-analysis of the empirical literature. Teach. Coll. Rec.115,1-47.

- Meenakshi, K. (2013). Importance of ICT in education. Journal of Research and Method in Education (IOSR-JRME), 1(4), 03-08, $\underline{\text { CrossRef }}$

- Mutsaers, E. J., Van der Zee, H., \& Giertz, H. (1998). The evolution of information technology. Information Management and Computer Security, 6(3), 115-26, CrossRef

- Nunnally, J. C. (1978). Psychometric theory ( $2^{\text {nd }}$ ed.), McGraw-Hill, New York. 
- Olayemi, A.O. \& Omotayo, K. (2012). ICT adoption and effective secondary school administration in Ekiti State. European Journal of Educational Studies, 4(1),59-64.

- Olibie, E. I., Ezoem, M.N. \& Ekene, U. S. (2014). Awareness of virtual learning among students of two Nigerian universities: Curriculum implications. International Journal of Development and Economic Stability, 2(1), 39-53.

- Olojo, O. J., Adewumi, M. G., \& Ajisola, K. T. (2012). E-Learning and its effects on teaching and learning in a global age. International Journal of Academic Research in Business and Social Science, 2(1), 203-210.

- Pallant, J. (2013). SPSS Survival Manual: A step by step guide to data analysis using SPSS for windows (Version 12). NSW: Allen \& Unwin, $\underline{\text { CrossRef }}$

- Pelet,J. E. \& Lecat, B. (2013). Virtual worlds as the next asset of virtual learning environments for students in business? International Journal of Virtual and Personal Learning Environments, 3(2), 59-76, CrossRef

- Radcliffe, D. (2002). Technological and pedagogical convergence work based and campus-based learning. [Electronic Version]. Educational Technology and Society, 5. Retrieved May 12, 2005.

- Root, D. and Thorpe, T. (2001), Refocusing collaboration technologies in the construction supply chain: Looking beyond the organization. Proc. Of ARCOM $7^{\text {th }}$ Annual Conference, University of Salford, Manchester, UK, 1,253-262.

- Stevens, J. (1996). Applied multivariate statistics for the social sciences ( ${ }^{\text {rd }}$ edn). Mahway, NJ: Lawrence Erlbaum.

- Tabachnick, B. G. \& Fidell, L. S. (2001). Using multivariate statistics (4 ${ }^{\text {th }}$ edn). New York: HarperCollins.

- Ukonu, U., Wogu J., \& Obayi, P. (2012). Problems and challenges facing the University of Nigeria's undergraduate students in the use of the UNN digital library. IOSR Journal of Humanities and Social Science (JHSS), 3(2), 4-12, CrossRef

- Umoh, G. I. \& Waribugo, S. (2016). Capacity planning and corporate productivity performance in the Nigerian aviation industry. International Journal of Business and Public Administration, 13(1), 21-35.

\section{Appendix A}

\begin{tabular}{|c|l|}
\hline S/N & \multicolumn{1}{|c|}{ ICT Adoption Practices } \\
\hline 1 & Our students sometimes learn through internet simulated tutorials without a physical tutor. \\
\hline 2 & Reading and sharing information in educational blogs \\
\hline 3 & Researching for course content information from on-line libraries \\
\hline 4 & $\begin{array}{l}\text { Learning facilitated and supported through the use of information and communications technology } \\
\text { applications }\end{array}$ \\
\hline 5 & Participating in online educational project teams requiring passwords \\
\hline 6 & Pinging/chats with colleagues about quizzes, examinations, and assignments \\
\hline 7 & Learning through network technologies from cell-phones \\
\hline 8 & Learning from self-assessed web-modules relating to personal needs. \\
\hline 9 & Registering courses on portals accessed by keyword search. \\
\hline 10 & Learning through online self-paced course contents with inter-linkage support \\
\hline 11 & $\begin{array}{l}\text { Students can easily read, view or listen to online academic programmes through their cell-phones, Mps, and } \\
\text { other Internet facilities. }\end{array}$ \\
\hline 12 & $\begin{array}{l}\text { Emphasis on social learning, collaboration and use of social software such as blogs, wikis, podcasts and } \\
\text { virtual worlds like, 'Second Life' 'WebTrain. }\end{array}$ \\
\hline 13 & Development of interactive communication protocols for information sharing. \\
\hline 14 & There is availability of multilingual software and web portals. \\
\hline 15 & We use 3D/4D visualization techniques as a communication tool. \\
\hline 16 & We use web based systems also as a learning space. \\
\hline 17 & We have flexible/scalable IT systems that are helpful in meeting changing students' demands. \\
\hline 18 & $\begin{array}{l}\text { Availability of indigenously developed software incorporating specific learning/teaching requirements for all } \\
\text { courses. }\end{array}$ \\
\hline 19 & The use of email and text messages to communicate with colleagues and students. \\
\hline
\end{tabular}


About the Authors

Sylva Waribugo is a scholar who graduated Summa Cum Laude at the University of Port Harcourt. Mr. Waribugo holds an M.Sc and MBA in Management. He is a member of the Nigeria Institute of Management and a fellow of two institutes, namely: the Institute of Public Management and the Institute of Chartered Economists of Nigeria. He is currently a lecturer and Doctoral scholar in the area of Operations Research in the Department of Management, University of Port Harcourt, Nigeria.

Success A.C. Anyanwu is a $\mathrm{PhD}$ degree holder in mathematics and a lecturer in the Faculty of Management Sciences, University of Port Harcourt. Having a strong background in business administration and management, and with teaching experience of over twenty five years, Anyanwu has taught mathematical applications in management sciences which span the areas of production management, operations research, quantitative methods in management, analysis for business decision making, business mathematics, organization and methods and business statistics. 